\title{
Interdisciplinary Research: An Important Contribution to Dementia Care
}

\author{
Tanja Louise Ibsen (D)', Siren Eriksen (iD) ${ }^{1,2}$ \\ 'Norwegian National Advisory Unit on Aging and Health (Aging and Health), Vestfold Hospital Trust, Tønsberg, Norway; ${ }^{2}$ Lovisenberg Diaconal \\ University College, Oslo, Norway \\ Correspondence: Tanja Louise Ibsen, Email tanja.ibsen@aldringoghelse.no
}

\begin{abstract}
Authorities and research institutions emphasise and encourage interdisciplinary research to meet complex societal health challenges as dementia. However, studies that describe an interdisciplinary approach for dementia research are limited. What does it take for research to become interdisciplinary? Is it enough to include researchers from different disciplines? This paper reflects on an interdisciplinary approach to dementia research. Based on existing literature and theories, we elaborate the concept of interdisciplinarity, and how the perspective can contribute and improve dementia care.
\end{abstract}

Keywords: interdisciplinary research, interdisciplinarity, dementia, dementia research

\section{Introduction}

The growing number of older adults in the world is leading to an increasing number of people with dementia and older adults in need of support from the society and the health care system. The Lancet Commission (2020) states that dementia is the greatest global challenge for health and social care in the 21 st century. ${ }^{1}$ There are several tasks, the resources are scarce, and this situation requires new ways of looking at the challenges of dementia care. ${ }^{1,2}$ To meet the complex societal health challenges, authorities and research institutions emphasise and encourage interdisciplinary research. ${ }^{3-6}$ Established researchers have also called for interdisciplinarity in dementia research. ${ }^{7}$ However, few studies are describing an interdisciplinary approach for dementia research. In this paper, we aim to shed light on how the perspective of interdisciplinarity could contribute to dementia research and thereby improve dementia care. We will examine the term "interdisciplinary research" and use practical examples within dementia care to elaborate how interdisciplinarity may influence the theoretical and practical approaches to care.

One definition of interdisciplinary research is

Communication and collaboration between researchers across academic disciplines. ${ }^{8}$

This opens up a broad understanding of interdisciplinarity, indicating that the main point is to combine disciplines. However, this may be confused with multidisciplinary research, where researchers from different scientific disciplines work in parallel with a common theme or problem. The findings are summarised, but without combining the disciplinary perspectives and creating a new and integrated approach to the field. ${ }^{9}$ Aboelela et a ${ }^{10}$ also emphasise collaboration between two or more scientific disciplines, but they add further specifications to their definition of interdisciplinary research:

a conceptual model that (...) integrates theoretical frameworks from those disciplines, uses study design and methodology that is not limited to any one field, and requires the use of perspectives and skills of the involved disciplines throughout multiple phases of the research process. ${ }^{10}$

In accordance with this definition, the different relevant disciplinary perspectives included must be valued to illuminate the research questions, and the scientific perspectives must all be incorporated throughout the entire research process. ${ }^{10}$ 
The differences in training, values, and experiences allow different disciplines to view the health challenges from different angles. Together, this could provide a broader view and better knowledge than multidisciplinary research. ${ }^{11-13}$

Interdisciplinarity will only succeed if different scientific disciplines manage to integrate their theoretical framework. ${ }^{10}$ In other words, it does not become interdisciplinary only because physicians, nurses, and physiotherapists are part of the same research team. Interdisciplinarity occur if the knowledge and understanding from the physiotherapist's science are allowed to expand the knowledge and understanding of the physician and the nurse, and vice versa. To describe it through a metaphor, it is not possible to put eggs, milk, butter, and flour into a bowl and think that it will automatically produce a cake. It is all about how the components interact and their transformational potential. ${ }^{14}$

\section{Research and Scientific Perspectives}

A diagnosis of dementia will impact the whole person and lead to a reduced capacity to carry out activities of daily living and a need for health care services. ${ }^{1,15,16}$ To understand and deal with this complex interaction of factors, it could be important to have an interdisciplinary approach to both research and practical care for people living with dementia. Because a topic or a field can be investigated from different scientific angles and different professions might have different scientific starting points, it may also lead to some challenges. To explain this, we present a simplified overview of different scientific perspectives in health research: natural sciences, human sciences, and social sciences. ${ }^{17,18}$ The perspectives are related to different scientific paradigms: constructivism, positivism, and pragmatism. ${ }^{19}$

Research from the perspective of natural sciences aims to explain cause and effect, and for instance, the reason why a disease occurs. ${ }^{20}$ Natural sciences are mostly based on a quantitative research design, grounded in the perspective of positivism. Studies based on natural sciences often investigate a large number of objects, focusing on the statistical numbers. The research aims to provide generalizable knowledge that is relevant and reliable for others than those under investigation. ${ }^{17,19}$

Research from the perspective of human sciences intends to explore human experiences, perspectives, and meaning. ${ }^{17,18,20}$ Human science is based on a qualitative research design grounded in constructivism. For instance, it focuses on the individual experiences expressed through interviews, human behaviour through observations, or exploring written texts. ${ }^{17,19}$

Research from the perspective of social sciences aims to understand the framework and context of a phenomenon, providing contextual knowledge that focuses on human interactions, social organisation, and societal structures. ${ }^{17,19,20}$ Social science uses both quantitative and qualitative design and is often grounded in pragmatism. ${ }^{17,19}$

\section{Practical Challenges of Dementia Care}

Health research aims to improve the practice and should, therefore, be based on practical questions and everyday care. Challenges in dementia care can arise at different levels, such as the individual, department, municipality, and national levels. Here, we present a case at the individual level to point at different possible scientific approaches to care.

In high income countries, a large proportion of nursing home residents have a dementia condition. ${ }^{21,22} \mathrm{~A}$ common situation in most nursing homes may be described like this:

Anna sits in the living room shouting "Help me! Help me!" with a loud voice to anyone walking past her in the ward. She seems distressed and worried. When someone offers to help her and asks what she needs help for, she is not able to explain. She just continues to shout, "Help me!", even though someone sits beside her and talks to her. Her shouting affects both the health care personnel, the other residents, and her next of kin.

To help Anna, we need to understand why she is behaving the way she does. From a natural science perspective, one will look for an explanation based on Anna's dementia diagnosis or other bodily indicators. ${ }^{17}$ One would elaborate on the causal interference between the symptoms and diagnosis. In the medical field, Anna's shouting will be called agitated behaviour. All the individuals diagnosed with dementia will experience neuropsychiatric symptoms during the course of dementia, which could explain Anna's shouting. ${ }^{23,24}$

Another explanation could be that she suffers from delirium, which is another medical condition. People with dementia are more prone to delirium than others because of their reduced brain function. This can lead to agitated 
behaviours and confusion. ${ }^{25}$ It is also important to determine the type of dementia and dementia severity, as this can influence behaviour. ${ }^{24}$ Other explanations could be pain or other bodily discomfort. ${ }^{1,26}$ Based on this, the type of treatment and eventually the need for medication should be investigated.

From the perspective of human sciences, one will elaborate on how Anna understands her situation. ${ }^{17}$ How she experiences the symptoms of dementia, how she experiences living in the nursing home together with her co-residents, how she experiences her relationship with the caregivers, how she experiences her daily life, etc. Shouting may occur as a response to her understanding or lack of understanding of the situation. ${ }^{27,28}$

From a social science perspective, one will focus on Anna in relation to the surroundings where she lives. ${ }^{17}$ Is it the elements in the context that leads to Anna's shouting? Is the ward where Anna lives created especially for people with dementia, or does the ward appear confusing and involve too many stimuli? Could there be elements about the environment that makes Anna afraid or anxious? How is Anna's relationship with her co-residents and health care personnel? Based on all these questions, one will elaborate whether there are organizational or relational elements that affect Anna's behaviour in any way. ${ }^{29}$

\section{Challenges in Interdisciplinary Research}

The behavioural symptoms in dementia, such as Anna's symptoms, require an interdisciplinary approach in both practice and research. Some of the challenges of conducting successful interdisciplinary research may be related to the diversity of the research strategies and methodologies, especially between natural sciences on one hand and the human and social sciences on the other. ${ }^{5,30}$ Thus, one can say that scientific perspectives, to some extent, appear as the borders that limit or restrict knowledge development. Language could also be a challenge, as it often influences our focus. Professional terminology, such as highly technical language, specific to one's field of expertise, could lead to misunderstandings or make others passive or feel less competent. As a result, important input from collaborative researchers could be left out, as they are unable to take part in the discussions, which in turn may affect the potential outcome of the research. ${ }^{5,12,31}$ Research is often characterised by conservatism as the researcher is committed to preserving the core of the discipline and guaranteeing proper standards of training and research. ${ }^{32}$ Consequently, academics and researchers may not be encouraged to move too far from the disciplinary borders, or they believe that "real" science most likely exists within their own discipline. ${ }^{32}$ Furthermore, it is claimed that there has been an asymmetry in the power balance between nature scientists and social- and human scientists, where the role and skills of social- and human scientists have usually been rated as "less scientific" than their colleagues within nature sciences. ${ }^{32,33}$

\section{What Promotes Interdisciplinary Research}

To meet or overcome these challenges, a foundation for interdisciplinary research to form a unified understanding of each other's scientific point of view is described. A constructive dialogue between researchers that promotes shared empathy, respect, and trust for scientific approaches other than their own must be established as guidelines. ${ }^{5,12,31,33}$ The goal of implementing such guidelines is to develop conditions or a climate that empowers the researchers to engage across disciplines and to reduce the differences between disciplinary jargon. ${ }^{33}$ Researchers have pointed at challenges in establishing what they call good cultural competence between different disciplines in clinical practice and found that humility is an important component. ${ }^{34}$

van Rijnsoever and Hessels ${ }^{6}$ have investigated the factors associated with interdisciplinary research. They found that more interdisciplinary research is being conducted by researchers who are women than by researchers who are men, and the authors recommend recruiting women. Further, they encouraged to attract staff from outside academia, with varied work experience, as several previous employers were found to stimulate interdisciplinary collaborations. They also recommend inspiring interdisciplinary research by better funding possibilities, as researchers stated that it was much easier to receive funding in disciplinary research projects, and thus such projects were prioritised. Finally, they suggest that taking part in interdisciplinary research should be rewarded with career advancement, which is now more likely for those who are specialised in single-discipline research. ${ }^{6}$ A lack of funding resources and career advancement are also emphasised as important elements hindering interdisciplinarity in other studies. ${ }^{11,12}$ 


\section{What Can the Transdisciplinary Perspective Add to Research?}

In the last decade, there has been an increased focus on user involvement in research. ${ }^{35,36}$ This is called translational research $^{37}$ or a transdisciplinary research model. ${ }^{9,35}$ Transdisciplinary research integrates academic researchers from different disciplines with non-academic participants, to co-create new knowledge and theory to achieve a common goal model. ${ }^{9,35}$ A transdisciplinary research model is considered suitable for addressing complex societal challenges, such as environmental and health research. ${ }^{9,31,35,38}$ It is expected that by involving the patients and the public in health research, the impact and relevance of the studies will increase, ${ }^{9,31,38}$ and there are good examples of such research. ${ }^{37,39,40}$ One example is a project where people with dementia and stakeholders have been involved in developing assistive technologies, including sensors and devices that may help older adults and people with dementia to be more independent in their everyday lives. ${ }^{39}$ Research on developing and making assistive technologies feasible may contribute to the postponing nursing home admission, as one of the solutions to meet a higher number of older adults in need of care in the future. ${ }^{39}$ Transdisciplinary research may be more time-consuming, which must be considered when planning the research project. $^{35,41}$

\section{Summary}

Interdisciplinary research is recommended to address complex health challenges, such as dementia. When the complexity of dementia is observed from different disciplinary angles, it can provide the field of practice with more relevant knowledge than disciplinary research alone. Researchers must be aware of how they relate to interdisciplinarity to ensure that all the involved scientific disciplines are incorporated in the research process. However, there are some challenges in achieving a fundamental understanding of interdisciplinary research, which may limit the potential for knowledge development. At the same time, the literatures reveal a comprehensive focus on how to strengthen the interdisciplinarity through respectful and equal communication between scientific disciplines and recommend strategies that support interdisciplinary collaborations. Finally, there is an increased focus on transdisciplinary research, involving end users in the research group. The user involvement from different levels within dementia care is expected to strengthen the relevance and implementation of the research.

\section{Disclosure}

The authors declare that they have no competing interests.

\section{References}

1. Livingston G, Huntley J, Sommerlad A, et al. Dementia prevention, intervention, and care: 2020 report of the Lancet Commission. Lancet. 2020;396(10248):413-446. doi:10.1016/s0140-6736(20)30367-6

2. Gjøra L, Strand BH, Bergh S, et al. Current and future prevalence estimates of mild cognitive impairment, dementia, and its subtypes in a population-based sample of people 70 years and older in Norway: the HUNT study. J Alzheimers Dis. 2021;79(3):1213-1226. doi:10.3233/jad201275

3. Boon M, Van Baalen S. Epistemology for interdisciplinary research - shifting philosophical paradigms of science. Eur J Philos Sci. $2019 ; 9(1): 16$. doi:10.1007/s13194-018-0242-4

4. Klein JT. Evaluation of interdisciplinary and transdisciplinary research: a literature review. Am J Prev Med. 2008;35(2 Suppl):S116-S123. doi:10.1016/j.amepre.2008.05.010

5. Tobi H, Kampen JK. Research design: the methodology for interdisciplinary research framework. Qual Quant. 2018;52(3):1209-1225. doi:10.1007/ s11135-017-0513-8

6. van Rijnsoever F, Hessels L. Factors associated with disciplinary and interdisciplinary research collaboration. Res Policy. 2011;40(3):463-472. doi:10.1016/j.respol.2010.11.001

7. O'Connor D, Phinney A, Smith A, et al. Personhood in dementia care: developing a research agenda for broadening the vision. Dementia. 2007;6 (1):121-142. doi:10.1177/1471301207075648

8. Albert M, Friesen F, Rowland P, Laberge S. Problematizing assumptions about interdisciplinary research: implications for health professions education research. Adv Health Sci Educ Theory Pract. 2020;25(3):755-767. doi:10.1007/s10459-019-09911-7

9. OECD. Addressing Societal Challenges Using Transdisciplinary Research. OECD Science, technology and industry policy papers; Vol. 8, 2020.

10. Aboelela SW, Larson E, Bakken S, et al. Defining interdisciplinary research: conclusions from a critical review of the literature. Health Serv Res. 2007;42(1 Pt 1):329-346. doi:10.1111/j.1475-6773.2006.00621.x

11. Bruzzese JM, Usseglio J, Goldberg J, Begg MD, Larson EL. Professional development outcomes associated with interdisciplinary research: an integrative review. Nurs Outlook. 2020;68(4):449-458. doi:10.1016/j.outlook.2020.03.006

12. Gohar F, Maschmeyer P, Mfarrej B, et al. Driving medical innovation through interdisciplinarity: unique opportunities and challenges. Front Med. 2019;6(35). doi:10.3389/fmed.2019.00035 
13. Portacolone E, Berridge C, Johnson KJ, Schicktanz S. Time to reinvent the science of dementia: the need for care and social integration. Aging Ment Health. 2014;18(3):269-275. doi:10.1080/13607863.2013.837149

14. McKenna HP. Nursing and interdisciplinary research: phoenix or dodo? J Multidiscip Healthc. 2020;13:1075-1078. doi:10.2147/jmdh.S262514

15. Gale S, Acar D, Daffner K. Dementia. Am J Med. 2018;131(10):1161-1169. doi:10.1016/j.amjmed.2018.01.022

16. World Health Organization. Dementia. Available from: http://www.who.int/mediacentre/factsheets/fs362/en/. Accessed February 11, 2022.

17. Polit F, Beck C. Nursing Research, Generating and Assessing Evidence for Nursing Practice. 11 ed. Wolter Kluwer; 2020.

18. van Manen M. Researching Lived Experience. Human Science for an Action Sensitive Pedagogy. 2nd ed. Routledge Taylor \& Francis Group; 2016.

19. Teddlie C, Tashakkori A. Foundations of Mixed Methods Research: Integrating Quantitative and Qualitative Approaches in the Social and Behavioral Sciences. SAGE; 2009:387.

20. Kleinman A. The Illness Narratives. Basic Books, Inc., Publishers; 1998.

21. Toot S, Swinson T, Devine M, Challis D, Orrell M. Causes of nursing home placement for older people with dementia: a systematic review and meta-analysis. Int Psychogeriatr. 2017;29(2):195-208. doi:10.1017/s1041610216001654

22. Prince M, Wimo A, Guerchet M, Ali G-C, Wu Y-T, Prina M. World Alzheimer report 2015: the global impact of dementia: an analysis of prevalence, incidence, cost and trends; 2015:82s.

23. Selbæk G, Engedal K, Benth J, Bergh S. The course of neuropsychiatric symptoms in nursing-home patients with dementia over a 53-month follow-up period. Int Psychogeriatrics. 2014;26(1):81-91. doi:10.1017/S1041610213001609

24. Gerlach LB, Kales HC. Managing behavioral and psychological symptoms of dementia. Psychiatr Clin North Am. 2018;41(1):127-139. doi:10.1016/j.psc.2017.10.010

25. Fong TG, Davis D, Growdon ME, Albuquerque A, Inouye SK. The interface between delirium and dementia in elderly adults. Lancet Neurol. 2015;14(8):823-832. doi:10.1016/s1474-4422(15)00101-5

26. Tible OP, Riese F, Savaskan E, von Gunten A. Best practice in the management of behavioural and psychological symptoms of dementia. Ther Adv Neurol Disord. 2017;10(8):297-309. doi:10.1177/1756285617712979

27. Førsund L, Grov E, Helvik A, Juvet L, Skovdal K, Eriksen S. The experience of lived space in persons with dementia: a systematic meta-synthesis. BMC Geriatr. 2018;18:33. doi:10.1186/s12913-017-2456-0

28. Eriksen S, Helvik A-S, Juvet L, Skovdahl K, Førsund L, Grov E. The experience of relations in persons with dementia: a systematic meta-synthesis. Dement Geriatr Cogn. 2016;42:342-368. doi:10.1159/000452404

29. Nordin S, McKee K, Wijk H, Elf M. The association between the physical environment and the well-being of older people in residential care facilities: a multilevel analysis. J Adv Nurs. 2017;73(12):2942-2952. doi:10.1111/jan.13358

30. Barnett T, Pfeiffer DU, Ahasanul Hoque M, et al. Practising co-production and interdisciplinarity: challenges and implications for one health research. Prev Vet Med. 2020;177:104949. doi:10.1016/j.prevetmed.2020.104949

31. Rodriguez FS, Jackson J, Ware C, Churchyard R, Hanseeuw B. Interdisciplinary and transdisciplinary perspectives: on the road to a holistic approach to dementia prevention and care. J Alzheimers Dis Rep. 2020;4(1):39-48. doi:10.3233/adr-180070

32. Mazzocchi F. Scientific research across and beyond disciplines: challenges and opportunities of interdisciplinarity. EMBO Rep. 2019;20(6). doi:10.15252/embr.201947682

33. Brown R, Werbeloff L, Raven R. Interdisciplinary Research and Impact. Glob Chall. 2019;3(4):1900020. doi:10.1002/gch2.201900020

34. Fisher-Borne M, Cain JM, Martin SL. From mastery to accountability: cultural humility as an alternative to cultural competence. Soc Work Educ. 2015;34(2):165-181. doi:10.1080/02615479.2014.977244

35. Pineo H, Turnbull ER, Davies M, et al. A new transdisciplinary research model to investigate and improve the health of the public. Health Promot Int. 2021;36(2):481-492. doi:10.1093/heapro/daaa125

36. Tierney E, McEvoy R, O'reilly-de Brún M, et al. A critical analysis of the implementation of service user involvement in primary care research and health service development using normalization process theory. Health Expect. 2016;19(3):501-515. doi:10.1111/hex.12237

37. Verbeek H, Zwakhalen SMG, Schols J, Kempen G, Hamers JPH. The living lab in ageing and long-term care: a sustainable model for translational research improving quality of life, quality of care and quality of work. J Nutr Health Aging. 2020;24(1):43-47. doi:10.1007/s12603-019-1288-5

38. Miah J, Dawes P, Edwards S, Leroi I, Starling B, Parsons S. Patient and public involvement in dementia research in the European Union: a scoping review. BMC Geriatr. 2019;19(1):220. doi:10.1186/s12877-019-1217-9

39. Holthe T, Casagrande FD, Halvorsrud L, Lund A. The assisted living project: a process evaluation of implementation of sensor technology in community assisted living. A feasibility study. Disabil Rehabil Assist Technol. 2020;15(1):29-36. doi:10.1080/17483107.2018.1513572

40. Mann J, Hung L. Co-research with people living with dementia for change. Action Res. 2019;14(4):573-590. doi:10.1177/1476750318787005

41. Grates MG, Heming AC, Vukoman M, Schabsky P, Sorgalla J. New perspectives on user participation in technology design processes: an interdisciplinary approach. Gerontologist. 2019;59(1):45-57. doi:10.1093/geront/gny112

\section{Publish your work in this journal}

The Journal of Multidisciplinary Healthcare is an international, peer-reviewed open-access journal that aims to represent and publish research in healthcare areas delivered by practitioners of different disciplines. This includes studies and reviews conducted by multidisciplinary teams as well as research which evaluates the results or conduct of such teams or healthcare processes in general. The journal covers a very wide range of areas and welcomes submissions from practitioners at all levels, from all over the world. The manuscript management system is completely online and includes a very quick and fair peer-review system. Visit http://www.dovepress.com/testimonials.php to read real quotes from published authors.

Submit your manuscript here: https://www.dovepress.com/journal-of-inflammation-research-journal 